\title{
A Reflection on the Past Decade
}

The following discussion offers a perspective about the major accomplishments of IASSIST over the past decade. Particular attention is paid to areas that are recognized as strengths of the organization and in which there have been notable successes. Many of the actions and outcomes in these areas flow from the goals embraced by IASSIST at the beginning of the 1990's. It is hoped that this discussion will assist in reviewing these goals and in setting directions for the future.

Most of the evidence in this summary is found in the business and program of the annual conferences of IASSIST. For many of our members, the IASSIST conference is a time to learn about new products, standards, services, and technology. These meetings keep IASSIST members at the forefront of our field. Concomitantly, the direction of the profession both is reflected in the issues of these conferences and is shaped by the discourse and outcomes of these meetings. Therefore, IASSIST conferences are an important source of evidence when considering the progress of this organization.

Six topics are discussed below that touch on the values expressed in the goals of IASSIST. While these topics are not strictly a re-expression of these goals, one can nevertheless find elements of the original goals in each of these six areas.

\section{The Pulse of the Membership}

The size of the membership has remained fairly stable over the past decade. While some have allowed their membership to lapse, overall there have been slightly more gains than losses. New members came from two primary sources. First, there has been an increase in the number of Europeans joining IASSIST, many of whom work in national data archives. Secondly, professionals new to data services, many working in academic libraries, account for the other membership gains.

A consorted effort was made in the early 1990's to expand membership among the staff of data archives. In 1993 under the direction of the UK Data Archive Director, many Archive staff attended IASSIST in Edinburgh. This experience demonstrated the value of IASSIST to data archive staff and equally important, these new
By Chuck Humphrey*

members brought a fresh enthusiasm to the organization. In subsequent years, several national data archives have supported their staff to attend the IASSIST conference. One encouraging indicator of this new commitment is that European attendance at IASSIST conferences held in North America has increased in recent years.

In conjunction with this growth of European members, many participants joined IASSIST after attending the ICPSR Summer Program workshop on social science data services. For this group, IASSIST serves as an organization where they can continue their professional development and can network with other data professionals. Many of these new members are the only individuals on their campuses providing data services. IASSIST is the one organization to which they belong where they find colleagues doing the same kind of work that they do.

During the past decade, structural changes occurred in several universities that altered the institutional location of data services. Computing centres that had been actively supportive of social science data services, for example, Princeton University, Northwestern University, and the University of Alberta, began divesting themselves of client services. The paradigm of central computing centres shifted from a services-based to a utility-driven organization. Under this model, computing became another outlet in the offices and labs on campus. Along with the light switch and the power and phone outlets, institutions added a computing network outlet. While computing centres became uninhabitable for data services, academic libraries welcomed the IT expertise of data services staff. In many instances, libraries absorbed data services that had become orphaned by the movement toward utility-driven computing centres.

IASSIST members played a supportive role in the relocation of data services in several universities during these times of structural change. Our members work in a rich variety of organizational settings and consequently, there is a wide range of models for providing data services. One model that was imitated by a number of institutions was an amalgamation of government information, maps, 
and data into a single administrative unit. This saw the convergence of support for statistical and spatial data.

Another significant environmental change having an impact on the institutional location of data services was the digital library initiative. This movement started to take root in academic libraries at the same time that several social science data services were moved into libraries. The digital library seemed to legitimize the incorporation of data services in the eyes of some academic library directors. Other directors recognized data as a valuable research resource that belongs in the library. The confusion between data services and the digital library unfortunately has never been resolved. For one thing, the digital library has been largely dominated by digitization projects and has failed to establish a strong connection with data services. Consequently, attention to the creation of digital collections has often overlooked data services as part of this movement.

As interest in social science data increased in areas of the globe outside of Australia, Europe and North America, IASSIST introduced two new initiatives to support these activities. A spin-off from these programs has been the addition of new members to IASSIST. First, an Outreach program, which is discussed in more detail below, was formally established during the 1996 conference in Minneapolis. This initiative seeks to support staff in countries where social science data services are just taking root. The second initiative was to create a new region for Africa within IASSIST. With a leadership base in the SADA and a growth in social science data activities on this continent, the prospects for new members from this region are encouraging

During this period, some turnover occurred in the membership due to career changes for some people and retirements for others. A testimony to the quality of the people in IASSIST is that contacts and friendships have been maintained with many of those who have changed careers. We also have the exemplar role model of a few retired members who have remained active in IASSIST!

As an organization, IASSIST needs to support professional data staff through training and upgrading, promoting social networking, contributing to standards development, disseminating information and knowledge, generating collaborative work, initiating and coordinating research, and offering a forum for professional issues. Many of these activities are conducted on a peer-to-peer basis, which makes IASSIST membership all the more important to professionals in data services.

\section{Communications}

Communication occurs on many fronts. There is memberto-member contact, official communiqués from the leadership of IASSIST, knowledge dissemination through the IASSIST Quarterly, and the public face of IASSIST. These communications require tools and organizational structure to occur, and the work and leadership of the Publications Committee has been essential is this regard.

IASSIST has provided an electronic means for members to communicate with one another through an email discussion list, which started in 1991 initially hosted by Princeton University before moving to Yale and then to Columbia, where it currently resides. This is a closed list to members and is used primarily by most members as an extended reference service where advice or information is sought from the wide realm of expertise among the membership.

In recent years, a membership directory has been produced annually from the records of the Treasurer and distributed to members in good standing. The Administrative Committee of IASSIST has decided not to give or sell mailing labels from this directory to advertisers, protecting the membership from unwanted junk mail. The primary purpose of the directory is for member-to-member contact.

In 1995, the IASSIST website was introduced to provide the organization with a public presence on the Internet. IASSIST members are good citizens of the Internet and the website was intended to reflect this spirit through the organization's support of open access to information. The website has undergone two phases of development. The initial phase focused on providing a description of the organization to the public. It tried to communicate what IASSIST is and why it is important. The second phase remodeled the site and incorporated material that members will also find useful. This design tried to balance the promotion of the organization with tools created by members that are important in the work that we do. As development continues with this phase, creative ways of using this medium are being sought to strengthen the organization's outreach to the wider data community and to deliver training and educational programs.

The IASSIST Quarterly (IQ) continues to be a print publication that is mailed to members in good standing. The production of the IQ, however, has long involved electronic stages in its preparation. In recent years, this electronic copy has been converted to PDF format and made available on the IASSIST website. The digital version of the IQ on the website is made available at approximately the same time as the print edition to the membership. Open access to the IQ contributes to the wider value of the Internet (as a public service of IASSIST), provides the organization with greater visibility, and shares the expertise of the membership more globally.

Other structural changes have happened in the organization that also improved communications within IASSIST. In 1998, a Treasury Group was organized creating three assistant treasurers located in three regions: the U.S., 
Europe and Canada. This new structure within IASSIST allowed for a flexible way of dealing with the bridge financing of conferences in these regions and for collecting membership fees. Beginning in 2000, the Membership committee was restructured around the Regional Secretaries. This change was introduced to provide a more direct contact with members in a region. Both of these initiatives were begun to establish a closer relationship between activities within IASSIST and its members.

The communication initiatives discussed above have been important for the life of this organization. Another assessment is found in the research conducted by Karsten Boye Rasmussen and Repke de Vries where they investigated IASSIST as a virtual community. Their findings suggest that IASSIST can make better use of network communication technology. Physical distances on this planet are an obstacle to our members meeting together, which is further discussed below under the topic of regionalism. Discovering a balanced use of network communications with in-person conferences is a priority of the organization.

\section{Metadata, Standards, and Technology}

Technology is a means to an end for those of us working in data services. There is no doubt, however, that technology at times seems to be in the driver's seat. This was particularly true in the early 1990's when many data services struggled with the migration of their data and documentation from mainframe environments to network technology.

IASSIST conferences throughout this past decade have held sessions dedicated to the issues of technological change in data services. In 1994 at the San Francisco IASSIST conference, prototypes of data extractors using a Web interface were demonstrated. These early examples confirmed the need for data documentation standards to facilitate Web extraction services.

Discussions around codebook standards evolved from roundtable discussions into interest groups in 1993 when a working group on Codebook Documentation of Social Science Data and a group to create documentation guidelines for data producers were established. In 1995, the Data Documentation Initiative (DDI) merged earlier working group interests and became the focal point for discussions about documentation standards within IASSIST. Many IASSIST members have contributed to the DDI standard and continue to lead in its development. The maturation of DDI is one of the major success stories of this organization.

The work of our European members through CESSDA and national data archive initiatives made further outstanding contributions in metadata and extraction tools. Among these projects was the integration of a major social science thesaurus with data catalogues, multi-catalogue searching over the Web using multiple languages, and Nesstar. These major contributions have been the focus of discussion at many IASSIST conferences over the past decade. Like DDI, they are successes to be celebrated.

The Ottawa IASSIST in 2003 held a session in which major data archives described how recent technology changes have been integrated into their data processing operations. This is another example of the convergence of changes in metadata, documentation, and technology. These new tools are changing the daily business of the major data archives.

The intellectual contributions of IASSIST members to these very significant developments over the past decade are achievements in which the organization can take great pride.

\section{Confidentiality, Intellectual Property and Privacy}

The issue of confidentiality and access is a long-standing topic in IASSIST. A delicate balance exists between the protection of the privacy of the individuals from whom data have been collected and claims for access to such data for legitimate research purposes. The millennium bug seemed to draw new public attention to the vulnerability of the massive amounts of data existing on individuals. One consequence has been a negative public reaction to the potential uses of digital information on individuals. Protective legislation has appeared recently in many jurisdictions that pose serious threats to legitimate research use of such data.

These concerns have been the topic of many plenary and concurrent sessions at IASSIST conferences. Institutional practices and procedures have been presented, such as the Norwegian model of a research data ombudsman. Technological fixes have been debated, including synthetic files and research data centres. At the Ottawa conference the issue of privacy was expanded to incorporate spatial as well as statistical data. These topics will not go away any time soon and IASSIST needs to continue addressing them to better inform the public, policy-makers, researchers, and the rest of the data community.

Data commodification surfaced over the past decade with the commercial success of the Internet. While the recent collapse of the dot-com industry has temporarily tempered interests in commercializing data, the issue itself will not go away. The next resurgence of e-business will drive a new wave to commodify data. Open scientific research is threatened by ownership claims to data. Consequently, this organization will need to steer the discussion about data ownership to one of data stewardship, and to be prepared to address ownership issues in terms of the barriers that it presents both to data access and to preserving data. 


\section{New Frontiers in Research Data}

The frontiers of social science research data continue to expand. One important new area has emerged from advances in computational methods in qualitative research. In fact, developments in this area have led to the formation of data services dedicated to qualitative data. Of particular note is Qualidata in the UK Data Archive, which is responsible for the acquisition, preservation, and dissemination of qualitative research data. Recent IASSIST conferences have held workshops and sessions on both the archiving of and providing data services for qualitative data. For example, a workshop was presented at the Ottawa conference in 2003 entitled, "Everything you ever wanted to know about preparing qualitative data, but were afraid to ask." In a sense, we have witnessed qualitative data come of age over this past decade with an expectation that secondary uses of this type of data will increase the overall value of qualitative data.

With the popularization of PC-based Geographic Information Systems in the 1990's, spatial data have become another rapid growth area in social science data. The affiliated use of geo-referenced statistical data with corresponding spatial data has added new demands for aggregate statistics from data services. Starting slowly in the early 1990's, GIS is approaching tidal wave strength as applications for spatial analysis sweep across social, health, economic, business, and educational research. IASSIST conferences have incorporated spatial data as a focal topic in recent years. The theme of the 2000 conference in Evanston was "Data in the Digital Library: Charting the future for social, spatial and government data." In 2003, a plenary was dedicated to spatial data in additional to concurrent sessions that dealt with GIS data issues.

Historical data have always been part of social science data interests in IASSIST. More recently, the development of public use microdata files from historical censuses has taken on new prominence. Following the success of the IPUMS project at the University of Minnesota, a new international historical census microdata program has emerged, IPUMS-International. These projects are contributing a wealth of new data for researchers. An additional spin-off from these projects is a network of collaboration between researchers and professionals in data services.

All three of these new data frontiers share metadata, preservation and access issues with existing social science data. The developments in DDI have been applied in the IPUMS project. Furthermore, enhancements to the DDI standard have resulted from the challenges of documenting these historical data sources. Similarly, the lessons, methods, and tools used in documenting quantitative data are being adopted with qualitative data. Again, unique aspects of qualitative data are contributing to metadata practices established for quantitative data. The archiving of spatial data lags behind other social science data types. However, many GIS researchers are now looking upon the preservation of spatial data as an extension of other social science data. IASSIST can play an important role in this development.

These three data areas warrant special mention because of their growth and contribution to new research in the social sciences. This does not, however, detract from the continued developments in quantitative data in the social sciences. Projects in these areas continue to see major advancements and include issues such as synthetic data, probabilistic linkage of large administrative databases, and the management of large consumer expenditure databases. Activities in these areas will continue to challenge IASSIST members to find appropriates ways of preserving and providing access to these data.

\section{Outreach and Regionalization}

Beginning in 1996, the IASSIST Administrative Committee initiated intentional outreach to support participants financially from countries just developing data archives and services. Post Cold War changes in Europe have resulted in the emergence of a number of new national data archives. Similarly, the post apartheid period in South Africa saw the development of the SADA. IASSIST has been supportive of the staff from these new archives. Some financial assistance has been made available to encourage their participation in our conferences. In addition, conference programs have included opportunities for speakers from new data archives. This has helped build contacts for those new to data services and archiving as they work to establish a network of professional connections. The work of the International Outreach Committee, in collaboration with IFDO, UNESCO, and the conference host-institutions, has been another IASSIST success story.

With social science data services and archives expanding around the globe, the reliance on an annual conference to keep the community connected is not as effective as it once was. While the size of the community remains relatively small, the distances of worldwide participation create serious difficulties. One approach worth examining is the formation of strong regional IASSIST communities structured around the Membership Committee and Regional Secretaries. In a sense, Europe has been functioning like this since the formation of CESSDA and its introduction of expert seminars. Similarly, the biennial meeting of the ICPSR Official Representatives has served a similar function in convening mostly North Americans outside of IASSIST conferences. Ways of engaging members to meet within regions without eroding the attendance at annual IASSIST conferences need to be explored.

\section{Conclusion}

IASSIST remains a membership-based organization committed to institutional solutions to preserving and 
providing access to data. The mission of IASSIST has not diminished over the past decade. If anything, its mandate has expanded as a result of the changes discussed above. Professional development will remain as important tomorrow as it has been over the past ten years. IASSIST clearly has a significant role to play in this area. Furthermore, a "voice for data" will be needed on the international scene tomorrow as much as it is today. The representation by IFDO and IASSIST this past year to get research data incorporated within the UNESCO Charter on the Preservation of Digital Heritage is an example of the type of leadership required at the international level. Currently, advocacy for research data at the international level has very few voices, and the voices that do exist are without coordination. The Committee on Data for Science and Technology (CODATA) and IASSIST hold many of the same interests but rarely if ever share the same platform. IASSIST needs to look for strategic alliances with other organizations concerned about the preservation and access to research data.

The talents and capacity of the membership of IASSIST have made this a successful organization. We may be small in numbers; but everyone in our number, counts. The recruitment of gifted new members, whose vitality will carry organization's mission forward, is crucial to the future of IASSIST. 